Article

\title{
Improving the Teaching of Real Valued Functions Using Serious Games. Binary Who Is Who?
}

\author{
Sagrario Lantarón ${ }^{1}\left(\mathbb{D}\right.$, Mariló López ${ }^{1, *(\mathbb{D})}$, Susana Merchán ${ }^{1}$ and Javier Rodrigo ${ }^{2}(\mathbb{D}$ \\ 1 Departamento de Matemática e Informática Aplicadas a las Ingenierías Civil y Naval, Escuela de Caminos, \\ Canales y Puertos, Universidad Politécnica de Madrid, Profesor Aranguren, 3, 28040 Madrid, Spain; \\ sagrario.lantaron@upm.es (S.L.); susana.merchan@upm.es (S.M.) \\ 2 Departamento de Matemática Aplicada, E.T.S.I. Universidad Pontificia Comillas, Alberto Aguilera 25, \\ 28015 Madrid, Spain; jrodrigo@comillas.edu \\ * Correspondence: marilo.lopez@upm.es
}

Citation: Lantarón, S.; López, M.; Merchán, S.; Rodrigo, J. Improving the Teaching of Real Valued Functions Using Serious Games. Binary Who Is Who? Mathematics 2021, 9, 1239. https: / / doi.org/10.3390/ math9111239

Academic Editors: Francisco

D. Fernández-Martín,

José-María Romero-Rodríguez,

Gerardo Gómez-García and

Magdalena Ramos Navas-Parejo

Received: 11 April 2021

Accepted: 26 May 2021

Published: 28 May 2021

Publisher's Note: MDPI stays neutral with regard to jurisdictional claims in published maps and institutional affiliations.

Copyright: (c) 2021 by the authors. Licensee MDPI, Basel, Switzerland. This article is an open access article distributed under the terms and conditions of the Creative Commons Attribution (CC BY) license (https:/ / creativecommons.org/licenses/by/ $4.0 /)$.

\begin{abstract}
The study presented makes an original, new and exhaustive analysis of the adaptation of a classical board game which has been named Binary Who is Who? This proposal shows a very useful tool for the consolidation of mathematical concepts related to the study of real-valued functions that are treated in the different levels of the teaching of mathematics (first and second year of superior secondary studies and the first years of some university degrees). The use of games as a means for learning is the authors' proposal. The aim is to offer teachers the chance of using the games as a method of teaching mathematical concepts, as well as a motivating instrument for them. This game has been created to be played face-to-face in the classroom and it has also been programmed to create a video game which allows the students to play virtually.
\end{abstract}

Keywords: gamification; mathematical teaching methodologies; educative innovation; learning through video games; real-valued functions

\section{Introduction}

The objective of this proposal is to use the educational value of certain games for the presentation and consolidation of the knowledge of some concepts of the subjects of mathematics that students must know, and proficiency related to logical-mathematical reasoning. We want to offer students the opportunity to play and beat challenges as a way of working with the concepts of daily lessons in the classroom, as well as a way of training their reasoning abilities.

There have been studies that confirm that people are naturally playful and, thus, we are open to all proposals that are related to games and competition. The Dutch historian, Johan Huizanga, showed in his book Homoludens [1] that making tends to include games in culture and society. Thanks to works like this, game-based learning and gamification are being incorporated in sectors like education, business, and digital commerce, among others [2-10].

The basic ingredient of gaming consists of the challenge and what it can represent for the individual.

If the users consider that the game that is presented to them puts their abilities to the test, they will show interest in it and see how far they can get [11].

Focusing on the use of games for the teaching and learning of mathematics, it should be noted that a good game, a game that has well-defined rules and has an approach rich in logical content, needs to include, on one hand, certain mathematical concepts, and on the other hand, a type of analysis whose characteristics are very similar to those that are needed to solve typical problems of this science. Mathematics is, to a large extent, a game and the game can, in many cases, be analyzed by means of mathematical instruments. In games, we look for fun, the possibility to quickly perform actions, and competition. 
This can be used to establish interest of the students in mathematical concepts, and secure the learned concepts. In this work, we take advantage of stimuli and the motivation that the spirit of games can infuse in students [12] and they are used to introduce and reinforce certain concepts that form part of the curriculum of this subject in different levels of education. What is intended, as stated by Marín [13], is not to "ludify" education, but "to promote learning processes based on the use of games for the development of effective teaching-learning processes, which facilitate cohesion, integration, motivation for content, and enhance the creativity of individuals".

Some questions that are posed about proposals of this type are: Can games really be used in the teaching of mathematics? How? What games? What objectives can be achieved through the games? [14,15]. In the present article, these questions are answered through an exhaustive analysis of a concrete proposal made by the authors.

We support game-based learning in mathematics [16-23]. Iriondo-Otxotorena [24] already did in an experiment in which an introduction to algebra was proposed through the solving of puzzles and enigmas. Our experience allows us to affirm that it is necessary to incorporate new methodological tools that are attractive for students. It is very common for students to find the subject of mathematics difficult to understand, boring, and impractical, so they get discouraged, stop paying attention to the teachers' explanations, and neglect their studies.

The incorporation of games into the mathematics classroom can be done one of two ways: through traditional games and through digital ones [25-27]. This article presents the possibility of combining these two modalities, by creating a game that is based on a traditional one to be played in the classroom, but which also has been adapted digitally to be played online. This combination has made it possible to work using both perspectives, taking advantage of the benefits provided by both.

\section{Statement of the Problem}

The study of real functions of real variables is taught in high school programs and the first courses of scientific and technical degrees. The proposal that has been developed adapts the foundations of a classic game such as "Who is Who?" with the objective of using its educational value, mainly for the consolidation of knowledge related to the study of real functions of real variables. We want to offer students the opportunity to play and overcome challenges, for which their mathematical knowledge on this subject will be of great help, while providing teachers a tool that they can adapt to their needs and to help them improve performance in their classes. The adaptation of the game has been proposed so it can be played not only in the classroom with other students but also as a video game that allows students to play individually as many times as they want.

In most games, participants play to win, and to overcome the challenges that the game presents. To win the game that is presented, it is necessary to resort to skills that are related to mathematics, which students should know or are learning in their classes. In addition, they will have to observe the possibilities, deduce, generalize results, plan future options, etc., all elements necessary for their academic training.

Thus, with this proposal, we want to offer teachers and students the opportunity to use and create games with the purpose of working within the daily lessons in the classroom, as well as carrying out a training method for their reasoning abilities. This way, the presented proposal aims to answer the following questions:

- Do the creation and use of games in the classroom improve the mathematical skills of the students?

- Can mathematical contents of the curriculum be reinforced with the use of games?

We believe in the need for another form of education, in which the emphasis is placed on the essential skills of people, promoting creativity, personal initiative, and self-learning, and where educational innovations and initiatives are integrated, in which games have an important role to carry out. Guzmán [28] pointed out that the factor with the highest 
influence is the teaching method. The work to come is framed in this line: games as an adequate instrument to learn. In this case, we are focused on students of different ages.

\section{Materials and Methods}

\subsection{Theoretical Framework}

Undoubtedly, one of the teaching fields where more work remains to be done is that of mathematics. While in other scientific disciplines, there has been great advances in their teaching in recent years, mathematics classes are moving in the same direction but much more slowly. Still, they often remain unrelated to daily reality, becoming a cluster of mechanical and disconnected exercises. Therefore, we consider it important to develop new tools or adapt some existing ones that are useful and easy to implement in the classroom, and always related to the curriculum.

According to Brull and Finlayson [29], game-based learning allows students to participate and learn, enjoying the freedom to experiment and fail in an enjoyable environment. Learners have the opportunity to interact with experiences that keep them motivated. There is evidence that students involved in gamified environments improve their learning, and increase their motivation and engagement [30].

Werbach and Hunter's proposal [31] suggests that in order to create a successful game, three fundamental elements must be introduced: game components, mechanics, and dynamics. However, before choosing these elements, six steps must be followed: defining objectives, defining the desired behaviors, describing the type of players at whom the game is aimed, choosing the activities to be carried out, including an element of fun in the activities, and developing tools (Figure 1). Thanks to its structure, this methodology is flexible and can be adapted to almost any context, particularly mathematics. These steps, as explained below, have been followed in this work for the development of the proposal.

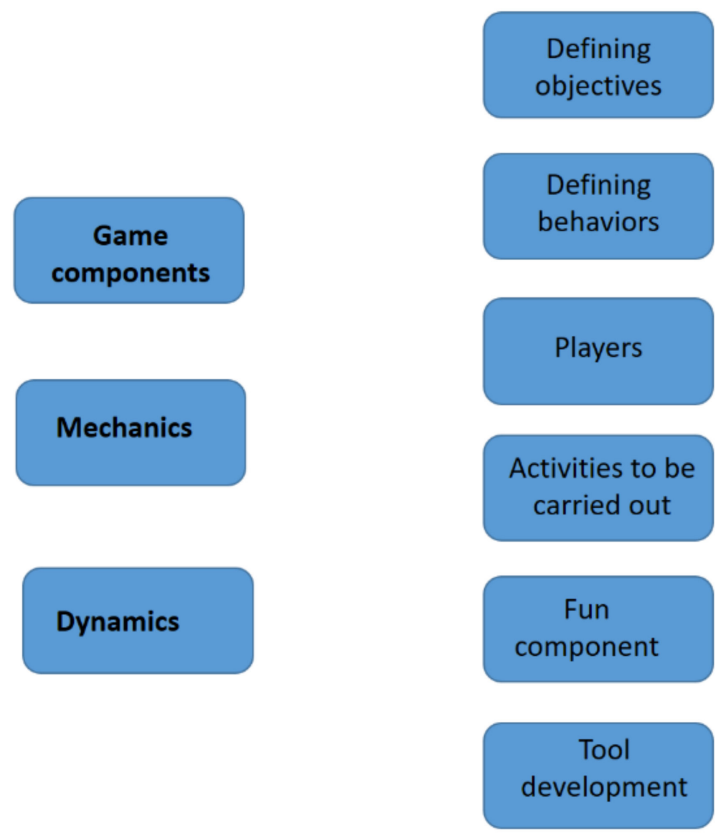

Figure 1. Steps to follow for the start-up process.

We have made several innovative educational proposals through games that allow us to understand and apply different concepts and mathematical theories.

The methodology applied in the project presented in this paper has been put into practice in different stages:

- Search for board games existing in the market that can be suitable from a mathematical point of view and adapted for teaching and learning of various topics. The choice 
of games which are familiar to students means that the game mechanics are already familiar to them.

- Creation of the new adaptations and proposals.

- Proposal of collaboration, to a group of students, in the physical creation of the game and rules.

- Approach and implementation in the classroom. The students play with the proposals and they are guided in their resolution through the mathematical approach.

- Development of a video game based on the proposal.

The educational courses and levels at which the project is directed include:

- Students of Mathematics II-second year Spanish science baccalaureate.

- Mathematical subjects related to the study of real functions of real variables from the first courses of different grades [32,33].

Concepts tackled:

- Numerical systems: decimal and binary.

- Didactic unit: real functions of real variables: domain, asymptotes, growth, decrease, maximum and minimum, among others.

These steps are outlined in Figure 2. A further development of them, specifically for the game developed, can be found in Section 2.3.
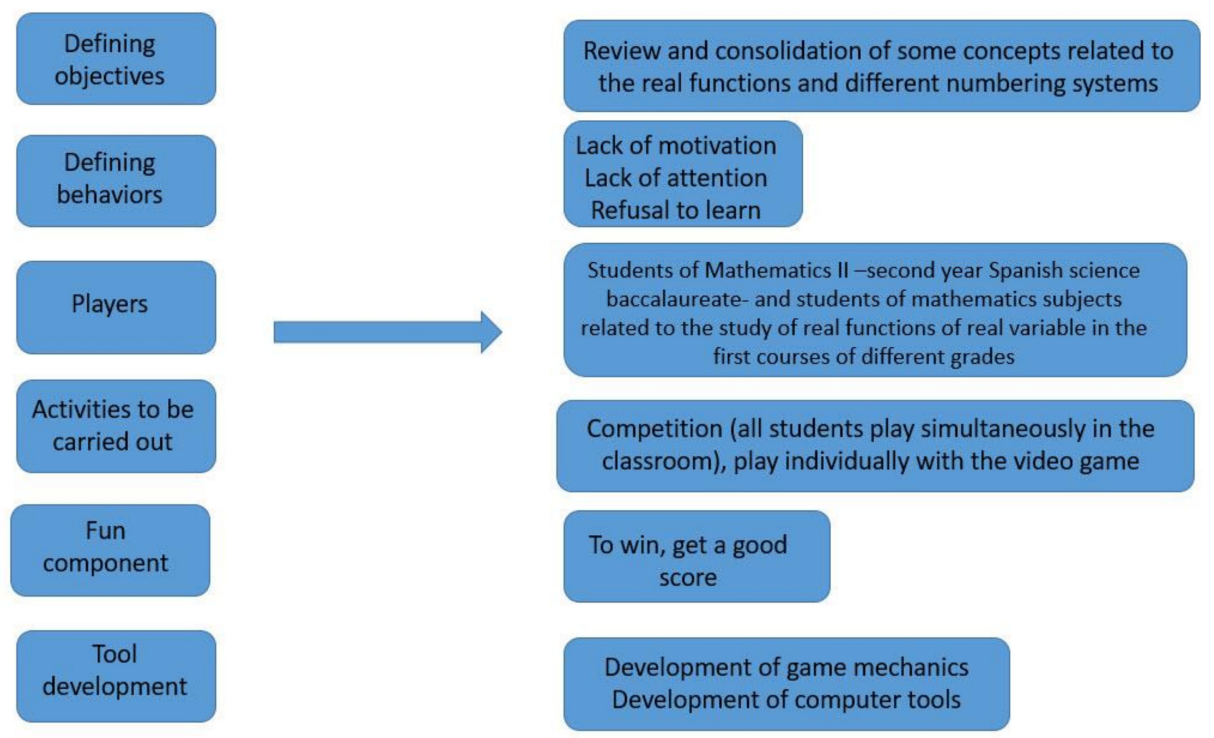

Figure 2. Steps to follow for the implementation of the game.

\subsection{Procedure: How Do You Work with Students?}

A session of "Games in the Classroom" will be presented to the students. For this, a group of students must be selected who will be involved in the realization of the game and in the organization of the game. The rest of the students will be those who will attend the game day as participants.

We will work with the group in charge of carrying out the proposal in various guided sessions.

When the day of the games session arrives, it will be adjusted to the agenda developed in class, and a competition will be proposed to the students in the classroom.

After the competition, the most appropriate mathematical strategy for the game played is explained. Mathematical contents that propose these strategies are remembered and students are allowed to analyze and think about them.

In this paper, we will focus on one of the games presented to the students: Binary Who is Who? We develop its design below. 


\subsection{Methodological Design}

The design of the game is based on the classic game Who is Who? whose rules are the following:

Each player has a series of cards with different characters. One of the participants chooses a card with a character and places it without the other player seeing it. The other player performs the same operation.

The objective of the game is to guess which character the other player has chosen.

In each turn, questions are asked about the features of the character the player wants to discover.

The other player answers these questions with a yes or no: if the player answers yes to a question, the cards of the characters that do not have that feature are removed; if the player answers no, the tiles of the characters that do have that feature are removed.

\subsubsection{Adaptation of the Game}

We wanted to adapt the idea of this game to the framework of the study of real functions of real variables, also including some other concepts such as numerical systems, specifically the binary system, which is of great use in computing (the same could be done with other topics).

For this, instead of characters, the idea is to work with defined functions both analytically and graphically. The first step is to choose the characteristics (traits in the classic game) about which the player will ask in order to discover the function chosen by the opponent. In our proposal, the selected ones are: sign of the function, range, monotony, continuity, derivability and existence of a vertical asymptote. Therefore, the six questions to be asked about the function, from which the desired function should be discovered, would be:

- Is it a non-negative function?

- Is it bounded?

- Is it monotone?

- Is it continuous?

- Is it derivable?

- Does it have a vertical asymptote?

Each of these questions will be answered with a yes (1) or a no (0). With this, each of the functions that are part of the game will have a definition in binary code that will consist of a vector of six digits, zeros or ones, depending on the answers to each of the questions to be asked for that function (Figure 3).
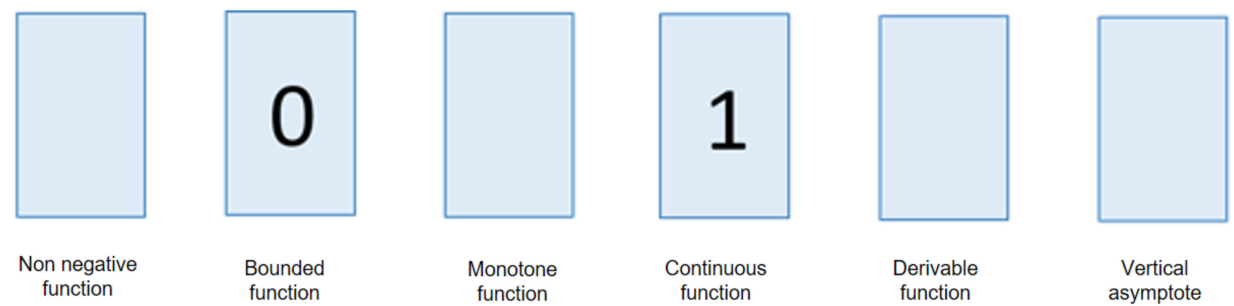

Figure 3. Binary vector that is updated each moment with the known data.

The number of possibilities that exist in the game will be the number of variations obtained with repetition of two elements $\{0,1\}$ taken from six in six: $2^{6}=64$ (Table 1 ). 
Table 1. Possible game responses.

\begin{tabular}{llllll}
\hline$(0,0,0,0,0,0)$ & $(0,1,0,0,0,0)$ & $(0,0,0,1,0,0)$ & $(0,1,0,1,0,0)$ & $(0,0,0,0,0,1)$ & $(0,1,0,0,0,1)$ \\
\hline$(1,0,0,0,0,0)$ & $(1,1,0,0,0,0)$ & $(1,0,0,1,0,0)$ & $(1,1,0,1,0,0)$ & $(1,0,0,0,0,1)$ & $(1,1,0,0,0,1)$ \\
\hline$(0,0,1,0,0,0)$ & $(0,1,1,0,0,0)$ & $(0,0,1,1,0,0)$ & $(0,1,1,1,0,0)$ & $(0,0,1,0,0,1)$ & $(0,1,1,0,0,1)$ \\
\hline$(1,0,1,0,0,0)$ & $(1,1,1,0,0,0)$ & $(1,0,1,1,0,0)$ & $(1,1,1,1,0,0)$ & $(1,0,1,0,0,1)$ & $(1,1,1,0,0,0)$ \\
\hline$(0,0,0,0,1,0)$ & $(0,1,0,0,1,0)$ & $(0,0,0,1,1,0)$ & $(0,1,0,1,1,0)$ & $(0,0,0,0,1,1)$ & $(0,1,0,0,1,1)$ \\
\hline$(1,0,0,0,1,0)$ & $(1,1,0,0,1,0)$ & $(1,0,0,1,1,0)$ & $(1,1,0,1,1,0)$ & $(1,0,0,0,1,1)$ & $(1,1,0,0,1,1)$ \\
\hline$(0,0,1,0,1,0)$ & $(0,1,1,0,1,0)$ & $(0,0,1,1,1,0)$ & $(0,1,1,1,1,0)$ & $(0,0,1,0,1,1)$ & $(0,1,1,0,1,1)$ \\
\hline$(1,0,1,0,1,0)$ & $(1,1,1,0,1,0)$ & $(1,0,1,1,1,0)$ & $(1,1,1,1,1,0)$ & $(1,0,1,0,1,1)$ & $(1,1,1,0,1,1)$ \\
\hline$(0,0,0,1,0,1)$ & $(0,1,0,1,0,1)$ & $(1,0,0,1,0,1)$ & $(1,1,0,1,0,1)$ & $(0,0,1,1,0,1)$ & $(0,1,1,1,0,1)$ \\
\hline$(1,0,1,1,0,1)$ & $(1,1,1,1,0,1)$ & $(0,0,0,1,1,1)$ & $(0,1,0,1,1,1)$ & $(1,0,0,1,1,1)$ & $(1,1,0,1,1,1)$ \\
\hline$(0,0,1,1,1,1)$ & $(0,1,1,1,1,1)$ & $(1,0,1,1,1,1)$ & $(1,1,1,1,1,1)$ & & \\
\hline
\end{tabular}

They seem like too many functions to generate. We will see in the next section that, thinking a bit, this number is largely reduced.

\subsubsection{Creation of the Game and Its Collaborations}

The first work to be done will be with the group of students who have agreed to collaborate in the realization of the game. They will be asked:

1. Carry out the necessary study to limit the number of functions that the game will offer. They must think what affirmative or negative answers to certain questions necessarily imply a certain response to other questions. For example, a non-continuous function implies that it will not be derivable either. With this, vectors of Table 1 with elements $(-,-,-,-0,1,-)$ must be removed from the list. Carrying out this work supposes an exhaustive review of all the theories of functions that are studied in the classroom from a new perspective. Students are also familiarized with the concept of binary numbers (in base 2) and, in general, with the different bases for expressing numbers.

A manageable number of possibilities, say 28 , is selected from Table 1 (see Table 2). This is a suitable number to play.

Table 2. Possible feasible game responses.

\begin{tabular}{cccccc}
\hline$(0,0,0,0,0,0)$ & $(0,1,0,0,0,0)$ & $(0,0,0,1,0,0)$ & $(0,1,0,1,0,0)$ & $(0,0,0,0,0,1)$ & $(1,0,0,0,0,0)$ \\
\hline$(1,1,0,0,0,0)$ & $(1,0,0,1,0,0)$ & $(1,1,0,1,0,0)$ & $(1,0,0,0,0,1)$ & $(0,0,1,0,0,0)$ & $(0,1,1,0,0,0)$ \\
\hline$(0,0,1,1,0,0)$ & $(0,1,1,1,0,0)$ & $(0,0,1,0,0,1)$ & $(1,0,1,0,0,0)$ & $(1,1,1,0,0,0)$ & $(1,0,1,1,0,0)$ \\
\hline$(1,1,1,1,0,0)$ & $(1,0,1,0,0,1)$ & $(0,0,0,1,1,0)$ & $(0,1,0,1,1,0)$ & $(1,0,0,1,1,0)$ & $(1,1,0,1,1,0)$ \\
\hline$(0,0,1,1,1,0)$ & $(0,1,1,1,1,0)$ & $(1,0,1,1,1,0)$ & $(1,1,1,1,1,0)$ & & \\
\hline
\end{tabular}

2. Define the 28 functions that will represent each of the 28 resulting vectors and which will be the game cards. This definition will sometimes be carried out through a formula (analytical definition of the function), and other times through a graph.

Once the functions are obtained, the chips of the game will be produced physically or virtually (if the game is going to be made with the support of a computer). Each of these cards will have an assigned definition of the function and the number in the decimal system that corresponds to the binary number of the vector that gave rise to the function. For example, the function associated with the vector $(0,1,0,0,0,0)$ will be written with the number $16=0 \times 2^{5}+1 \times 2^{4}+0 \times 2^{3}+0 \times 2^{2}+0 \times 2^{1}+0 \times 2^{0}$ (Figure 4 ). 

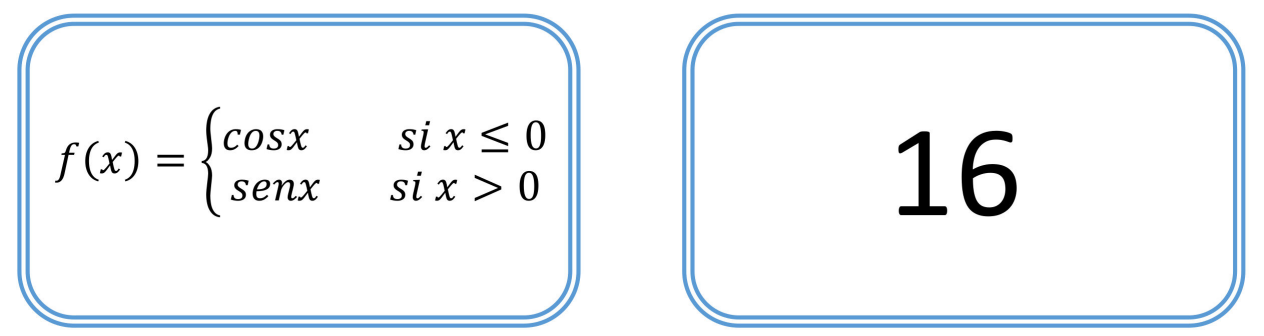

Figure 4. Image of an analytical game sheet.

This corresponds to a function that is not positive, that is bounded and that is not monotonous, nor continuous, nor derivable and it does not have vertical asymptotes.

The function associated with the vector $(1,0,0,0,0,0)$ has the written number $32=1 \times 2^{5}+0 \times 2^{4}+0 \times 2^{3}+0 \times 2^{2}+0 \times 2^{1}+0 \times 2^{0}$ (Figure 5).
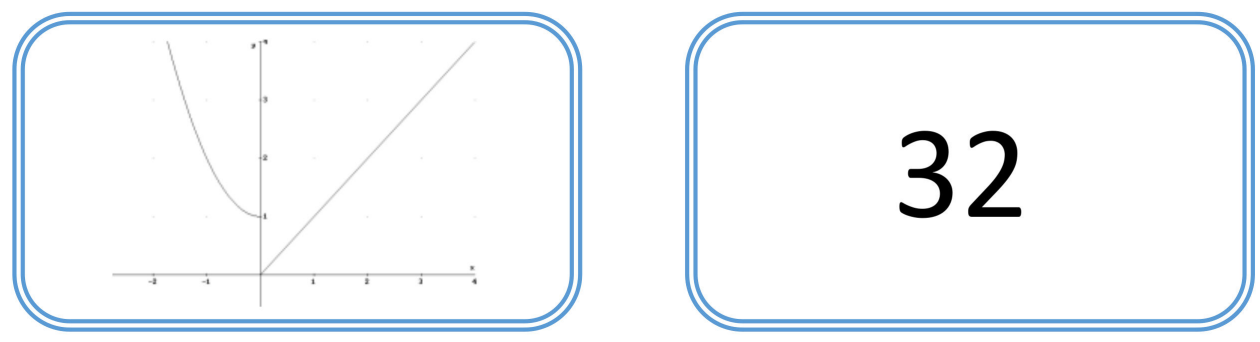

Figure 5. Image of a graphic card of the game.

This corresponds to a function that is non-negative and not bounded and is not monotonous, nor continuous, nor derivable and that has no vertical asymptotes.

\subsubsection{Development of the Competition}

There are several ways to introduce this game in the classroom. We have chosen one that allows all students to play simultaneously, so that no student is unable to participate. Each participant will have a template with the 28 cards corresponding to the functions of the game and a box of six positions to complete. In addition, the cards can be made in a digital format and will be shown to the participants through a projector. On this screen, the cards are projected on the side of the functions in an arrangement of rows and columns, and students are told that they are numbered from left to right and top to bottom. (Figure 6).

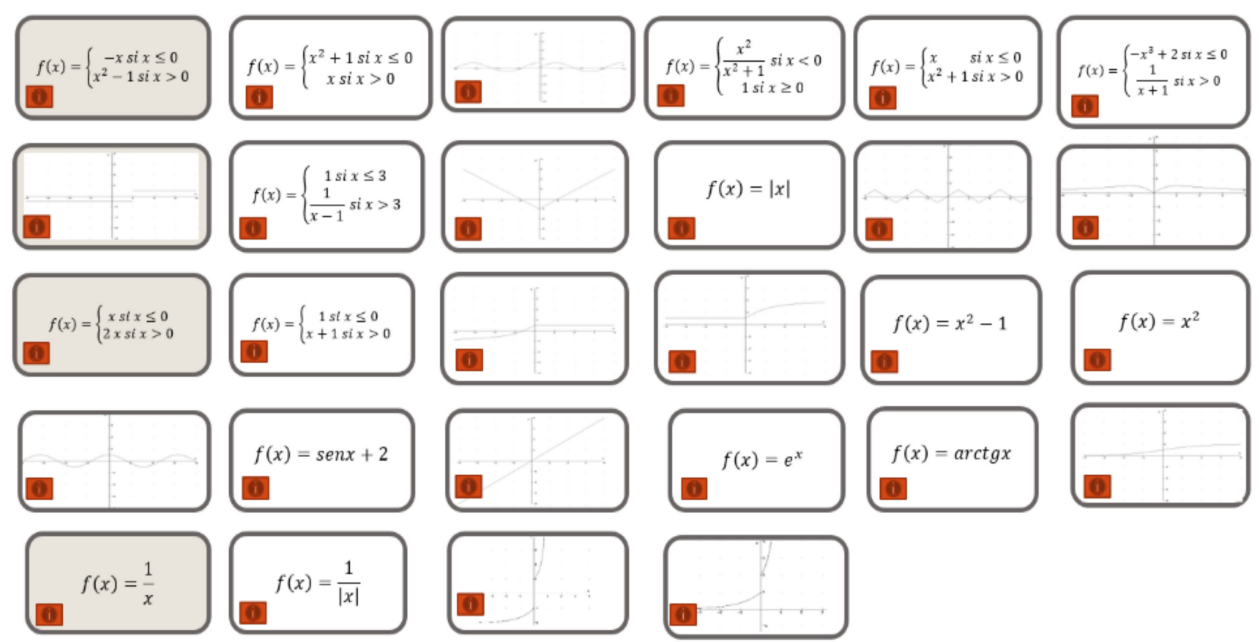

Figure 6. Projection in digital form of the functions selected for the game. 
Steps to follow:

- The students can see all the functions which make up the game. The teacher will select one of them (its associated number in the decimal system will be written on a piece of paper that will be saved without any participant seeing it).

- An orderly question time begins for the students. Each student will cross out the functions that do not match the indicated characteristic and, in addition, will be completing the vector of six positions with the answers that are obtained and applying their knowledge (some answers may implicitly give answers to other unasked questions).

- The moment that one of the students thinks that he/she knows the chosen function, he/she will select it on the screen and will give the number in the decimal system that corresponds to it. This means that the participant must change the vector of zeros and ones, corresponding to the answers to the questions asked, to the number in the corresponding decimal system.

- $\quad$ First, the tab of the chosen function will be flipped.

- If the numbers do not coincide, the student is eliminated and the game continues.

- If the numbers match, the teacher will see if it is the number saved at the beginning. If it is, there will be a winner of the game. Otherwise the student is eliminated and the game continues.

The search for a good game strategy makes the participants reflect broadly on the concepts related to the real functions of real variables:

A good knowledge of the theory allows the participant to ask the right questions that lead to a quick resolution. In the same way, one can make beneficial use of the questions asked by colleagues and the answers received. For example, if a student asked about the existence of vertical asymptotes, receiving an affirmative answer, it is supposed, for someone familiar with the subject, that the answers to continuity and derivability of the function will be negative. One can complete the sequence of the binary number without asking questions.

\subsection{Video Game}

It is an assumed fact that the current generation of students feels a great attraction to computer games. This can be used to motivate the teaching of mathematics [34,35]. In this way, we have adapted the proposed game to the virtual environment by programming a videogame that recreates the "Who's That Function" challenge. This allows the students to become acquainted with the concepts related to the study of functions in a proactive way and to improve their performance through the obtained marks in the online game.

The instructions are displayed in Spanish and the game has free access by the following link: https: / / flyingflamingo.itch.io/whos-that-function, accessed on 11 March 2021 (Figure 7).

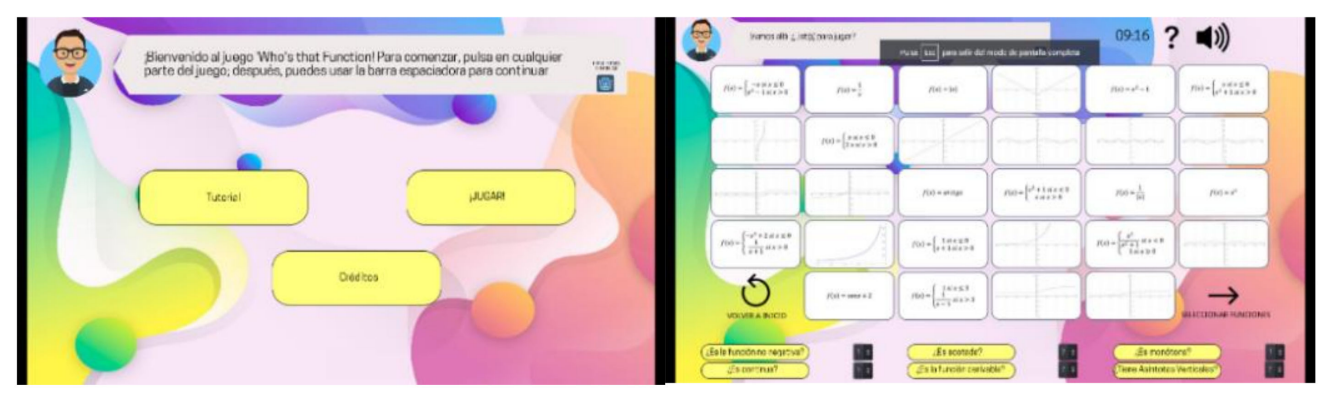

Figure 7. Screenshots of the online game. 
Technical Description:

- Programming language:

The game has been programmed by using Godot Engine, whose scripting language is GDScript (similar to the Python language). To execute it in the navigator, the system allows for creating an executable file translated to HTML5.

- Operative environment:

Any standard desktop navigator can serve as an operative environment. Therefore, the online game can be played on platforms such as GNU/Linux, Windows or MacOS. It has been tested in Firefox 82 and Chromium 85.

- $\quad$ Flow chart (see Figure 8):

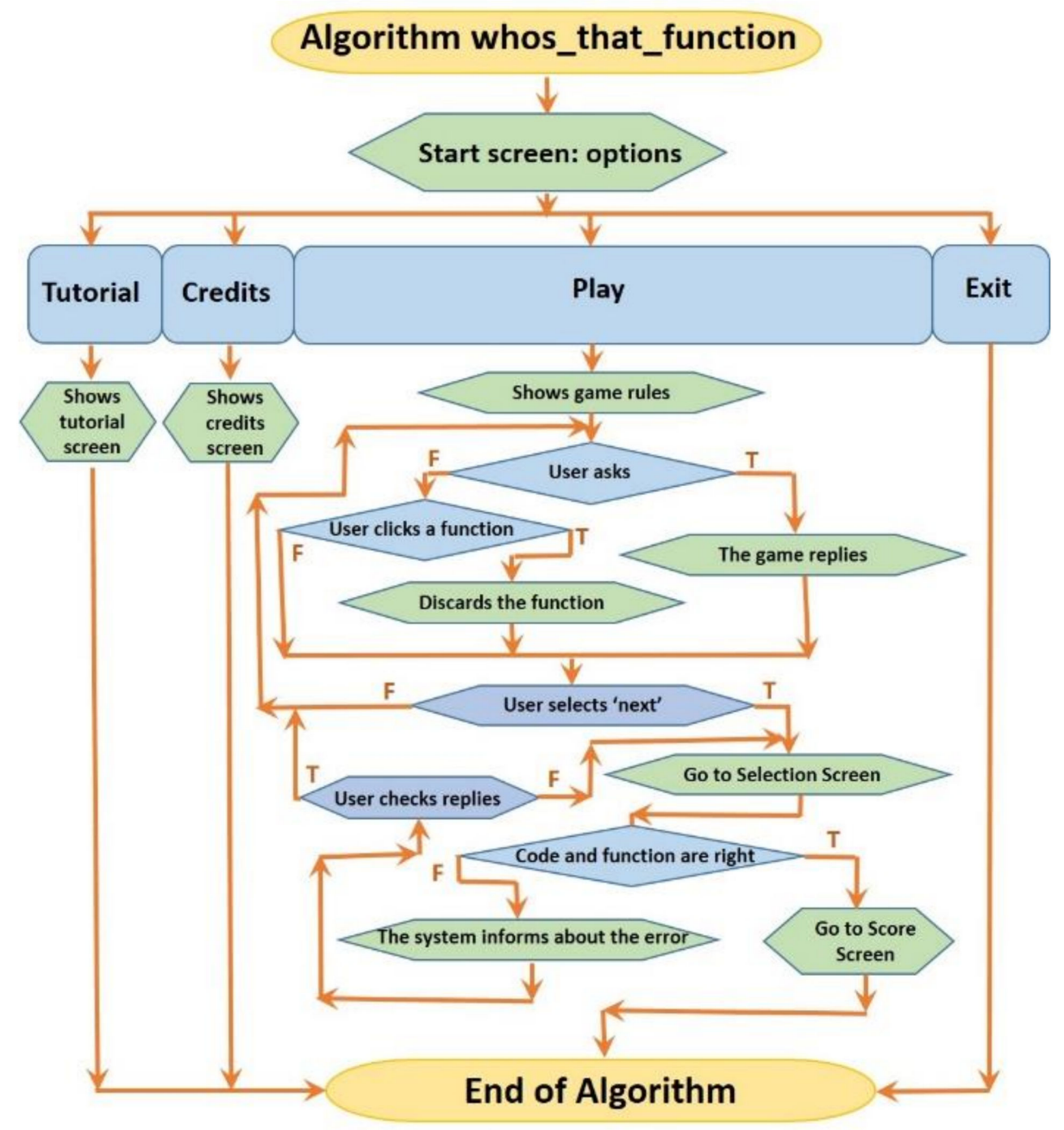

Figure 8. Flow chart for the "Who's That Function" online game.

\subsection{Educational Content}

The game to be implemented has been designed to be able to assess the students' knowledge once the analysis unit has been completed. The main contents of this didactic unit are:

Limits of functions

Calculation of asymptotes of a function

Continuity

Derivability

Growth and decay 
Concavity and points of inflection

Domain and range

Monotonicity

Intervals of constant sign, regions

Graphical representation

As explained above, the objective of the game is for the students to find out the function that has been previously selected either by the teacher if the game is played in the classroom, or by the computer, by answering six key questions.

It is essential that when given an analytical representation of a function, a student can produce its graphical representation, and also know how to specify its characteristics. This first objective is achieved by a student matching the function cards with their analytical and graphical representation. A student who is unable to match both representations will not receive a good result and will not score a mark.

The decision of which questions should be asked responds to the need to assess the maximum amount of key knowledge of the didactic unit. It is essential for the student to evaluate whether a function is continuous or has discontinuities. As such, one of the questions that may be asked is: Is the function continuous? After the game gives the answer to this question, the player must be able to eliminate the incorrect functions by applying their knowledge of continuity. Similarly, for the concept of the derivability of a function, there is the direct question: Is it derivable?

The calculation of the limits of a function and the concept of asymptotes are addressed by the question: Does it have a vertical asymptote? To correctly respond, the student must be able to manage these concepts both graphically and analytically.

The range of a function is reviewed with the question: Is it bounded? Growth and decay and monotonicity are analyzed with the question: Is it monotone?

To put the student's knowledge about regions of constant sign for a function into practice, they are asked the question: Is it a non-negative function?

Additionally, the game works with the theoretical implications of function properties. For example, a derivable function is continuous, a function with a vertical asymptote is not continuous in $\mathrm{R}$, a discontinuous function is not derivable, a function with a vertical asymptote will not be bounded, etc. The student must put this knowledge into practice. When playing in the classroom, using this knowledge will save time and allow the student to respond more quickly to the challenge. In the case of the video game, the format is designed to give the highest score to the player who gets the correct answer with the fewest questions asked.

The concepts of domain, concavity and points of inflection are not directly included in the questions asked in the game, but are addressed in a tangential way. For example, a common misconception among students is to think that, at a point where the function has a vertical asymptote, the function is necessarily undefined, or that a point of discontinuity does not necessarily belong to the domain of the function. Additionally, some students make the mistake of thinking that an inflection point marks a change in the growth of the function (e.g., from increasing to decreasing). The graphic cards in the game, as well as the teacher's guidance as the game is played, can be helpful in correcting these misunderstood concepts.

Additional content that is worked on in the game is the representation of a number in different bases (positional notation). This content is part of the number theory unit, which is useful for preparing students for technical degree programs such as computer engineering or mathematical engineering. Even though it is not present in the game cards, it is evaluated at the end of the game, since the students have to convert a number in base 2 to base 10 to obtain the final result.

Table 3 shows the most relevant information on the key mathematical concepts included in the game, their relationship with the game design and the score given to the players. 
Table 3. Concepts tackled in the game.

\begin{tabular}{|c|c|c|}
\hline Key Mathematical Concept & Game Design Element & Final Score \\
\hline $\begin{array}{l}\text { Being able to analyze the continuity of } \\
\text { a function. }\end{array}$ & $\begin{array}{c}\text { In the game, the student answers the } \\
\text { question: Is it continuous? }\end{array}$ & \multirow{7}{*}{$\begin{array}{l}\text { In the video game, getting the } \\
\text { function correct scores points. The } \\
\text { number of points decreases as the } \\
\text { number of attempts increases. }\end{array}$} \\
\hline $\begin{array}{l}\text { Being able to analyze the derivability of } \\
\text { a function. }\end{array}$ & $\begin{array}{l}\text { In the game, the student answers the } \\
\text { question: Is it derivable? }\end{array}$ & \\
\hline $\begin{array}{l}\text { Being able to calculate limits of functions and } \\
\text { asymptotes. Recognizing these concepts } \\
\text { through the visualization of the graph of } \\
\text { a function. }\end{array}$ & $\begin{array}{l}\text { In the game, the student answers the } \\
\text { question: Is there a vertical asymptote? }\end{array}$ & \\
\hline Being able to analyze the range of a function. & $\begin{array}{l}\text { In the game, the student answers the } \\
\text { question: Is it bounded? }\end{array}$ & \\
\hline $\begin{array}{l}\text { Being able to recognize the growth and decay } \\
\text { of a function and its monotonicity. }\end{array}$ & $\begin{array}{l}\text { In the game, the student answers the } \\
\text { question: Is it monotonous? }\end{array}$ & \\
\hline $\begin{array}{l}\text { Being able to analyze regions of constant sign } \\
\text { for a function. }\end{array}$ & $\begin{array}{l}\text { In the game, the student answers the } \\
\text { question: Is it a non-negative function? }\end{array}$ & \\
\hline $\begin{array}{l}\text { Being able to study a function through its } \\
\text { analytical or graphical representation. }\end{array}$ & $\begin{array}{l}\text { The function cards are offered in one of } \\
\text { two ways, mixing both in the set. }\end{array}$ & \\
\hline $\begin{array}{l}\text { Being able to recognize implications of } \\
\text { different characteristics of the function. }\end{array}$ & $\begin{array}{l}\text { The game allows the student to get the } \\
\text { function without answering all } \\
\text { the questions. }\end{array}$ & $\begin{array}{c}\text { Extra points will be given to the } \\
\text { player who gets the correct function } \\
\text { without having needed all the } \\
\text { answers. }\end{array}$ \\
\hline $\begin{array}{l}\text { Being able to change the base of a number } \\
\text { representation. }\end{array}$ & $\begin{array}{l}\text { Each function is assigned a number in } \\
\text { base 10, which must be guessed from a } \\
\text { number in base } 2 \text { obtained from the } \\
\text { answers of the game. }\end{array}$ & $\begin{array}{l}\text { In the video game, if the numbering is } \\
\text { correct, the player gets points. The } \\
\text { number of points decreases as the } \\
\text { number of attempts increases. }\end{array}$ \\
\hline
\end{tabular}

\section{Results}

The implementation of this proposal has been carried out during the course 2018/2019, on:

- four groups of eighty students each in their first year majoring in civil and territorial engineering at the Polytechnic University of Madrid (UPM) taking Calculus I.

- $\quad$ eight workshops with a capacity for twenty students of the 2nd year of high school in various educational centers of the Community of Madrid (Spain).

After the experience ended, in order to carry out an assessment of the opinions of the students and the results, a survey was carried out for all the participants (to both those who contributed to the creation of the game and those who played it). The survey and its analysis are attached in the Appendix A. It is worth mentioning the good evaluation of the students who were involved in the design of the game who, in a major way, valued very positively the learning that their accomplishment gave them.

Regarding the students who played the game, around $90 \%$ of them agreed or strongly agreed that the game helped them to understand the unit and be motivated by mathematics: $92 \%$ say it has helped them to review the concepts.

$84 \%$ consider it appropriate or very appropriate for their level.

$85 \%$ would use more of these types of games in the course.

$86 \%$ would find it appropriate to use these types of games in other subjects.

$87 \%$ have increased their interest in mathematics.

$90 \%$ would recommend the game.

We reached the objectives that we set ourselves and can be summarized as:

- Awaken the interest in learning mathematics.

- To enable students to apply the acquired concepts.

- Enhance skills based on mathematical reasoning: strategy, planning, decision making, etc. 
- Apply the dynamics and principles of games to improve the motivation, interest and involvement of students in subjects with mathematical content.

- Create a series of playful proposals (games) that promote mathematical knowledge and the playful approach to this science.

The achievement of the aforementioned objectives entails the facilitation of the students' learning process, which can be done through an enjoyable, playful, flexible, dynamic and interactive mechanism, which is expected to attract students and promote their involvement in the subject.

\section{Discussion and Conclusions}

We are sure that the actions proposed in this project will contribute to the approach of students towards understanding essential basic subjects in their studies. The application of games is highly motivating and is a good reinforcement if applied to mathematical subjects. In addition, it allows students to integrate and relate to each other since it promotes team actions.

The groups of students to whom we have presented the activity have shown great receptivity and an excellent understanding of the content presented, which has improved their perception of mathematical topics.

These good results are supported by the surveys presented to the participants (see the Appendix A). We emphasize that the students who collaborated in the realization of the game showed greater satisfaction with the experience and what it gave them.

As future actions, we want to involve students in the design or invention of new proposals (new games) where they must use the contents they have learned or are learning in the subjects related to mathematics. In this way, we want to stimulate creativity and mathematical knowledge.

\section{Patents}

The software shown in Section 2.4 has been registered in the Intellectual Property Registry. File number: 09-RTPI-08550.8/2020.

Author Contributions: Conceptualization, S.L., M.L., S.M. and J.R.; methodology, S.L., M.L., S.M. and J.R.; software, S.L. and M.L.; formal analysis, S.L., M.L., S.M. and J.R.; investigation, S.L., M.L., S.M. and J.R.; resources, S.L., M.L., S.M. and J.R.; data curation, S.L., M.L. and S.M.; writing-original draft preparation, S.L., M.L., S.M. and J.R.; writing—review and editing, S.L., M.L., S.M. and J.R. All authors have read and agreed to the published version of the manuscript.

Funding: This research has been carried out with the help of the project of educative innovation IE1920.0403: “From Game to Theory" (UPM).

Institutional Review Board Statement: Not applicable.

Informed Consent Statement: Not applicable.

Data Availability Statement: Not applicable.

Acknowledgments: The third author has been partially supported by project PDI2019-110712GB-100 of Ministerio de Ciencia e Innovación, Spain.

Conflicts of Interest: The authors declare no conflict of interest. The funders had no role in the design of the study; in the collection, analyses, or interpretation of data; in the writing of the manuscript, or in the decision to publish the results.

\section{Appendix A}

Survey conducted with students who participated in one way or another in the proposal. 
Survey on the activity "Binary Who is Who"

1. Rate from 1 to 5 your level of interest towards the Mathematics subject, where 1 is nothing and 5 is a lot.

Mark only one box.

$\begin{array}{lllll}1 & 2 & 3 & 4 & 5\end{array}$

2. Do you think that this game has helped you to better understand the functions? Rate from 1 to 5 , where 1 is not useful and 5 very useful.

Mark only one box.

$\begin{array}{lllll}1 & 2 & 3 & 4 & 5\end{array}$

3. Do you think this game has helped you to review the contents of the subject? Rate from 1 to 5 , where 1 is not useful and 5 very useful.

Mark only one box.

$\begin{array}{lllll}1 & 2 & 3 & 4 & 5\end{array}$

4. Do you think the difficulty of the game is appropriate to your level? Rate from 1 to 5 , where 1 is not adequate and 5 is very adequate.

Mark only one box.

$\begin{array}{lllll}1 & 2 & 3 & 4 & 5\end{array}$

5. Would you like to be able to have games of this style for other subjects of Mathematics? Rate from 1 to 5 , where 1 is I would not like it and 5 I would like it very much.

Mark only one box.

$\begin{array}{lllll}1 & 2 & 3 & 4 & 5\end{array}$

6. Would you like to be able to have games of this style for other subjects? Rate from 1 to 5 , where 1 is I would not like it and 5 I would like it very much.

Mark only one box.

$\begin{array}{lllll}1 & 2 & 3 & 4 & 5\end{array}$

7. Do you think this game has contributed to increasing your interest in Mathematics? Rate from 1 to 5 , where 1 is nothing and 5 a lot.

Mark only one box.

$\begin{array}{lllll}1 & 2 & 3 & 4 & 5\end{array}$

8. Would you recommend this game for students of your same level? Rate from 1 to 5 where 1 is not recommended and 5 highly recommended.

Mark only one box.

$\begin{array}{lllll}1 & 2 & 3 & 4 & 5\end{array}$

Attached is the analysis of the surveys made to the students of the 1st year of Civil and Territorial Engineering degree of the UPM (2018-2019 academic year):

(a) Students who participated in the making of the game.

Number of students who participated: 6 .

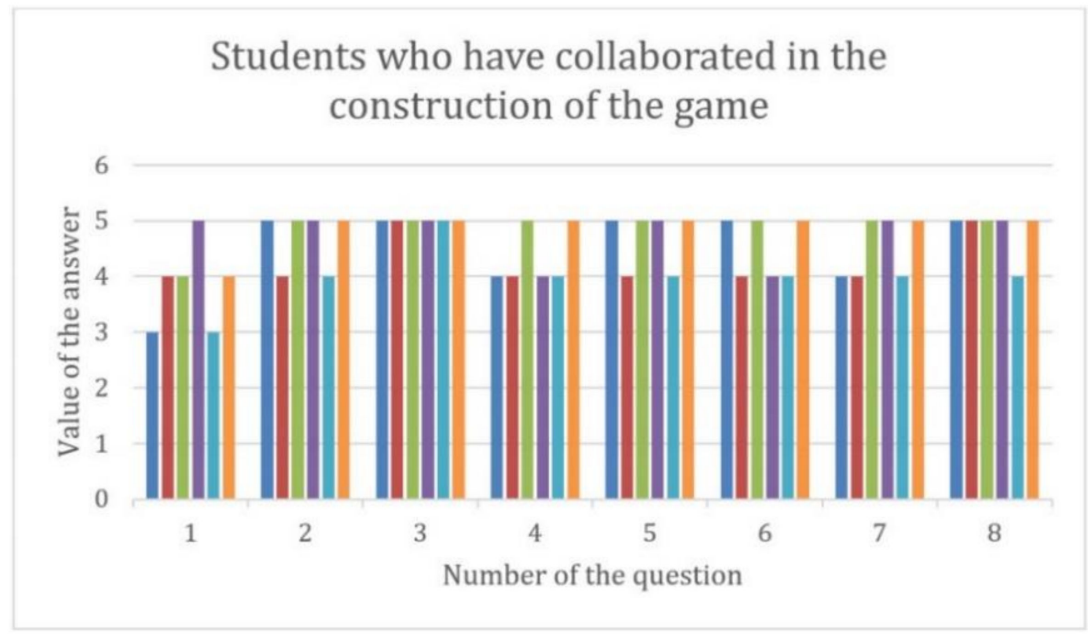

Figure A1. Results of the survey of the students who collaborated in the making of the game.

(b) Students who have played "Binary Who is Who". 
Number of students surveyed: 100 .

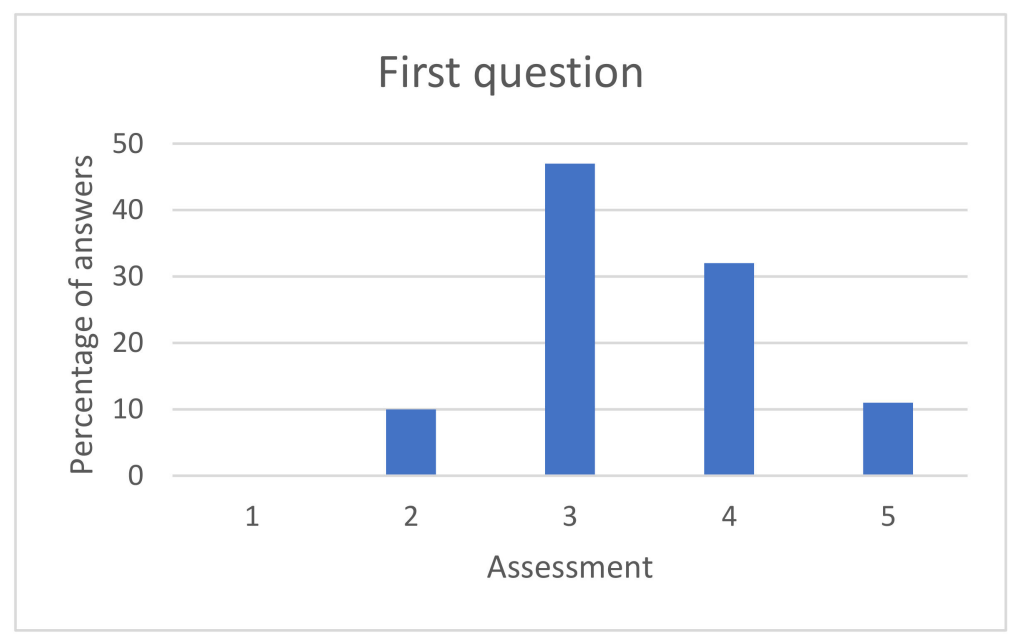

Figure A2. Results of question 1.

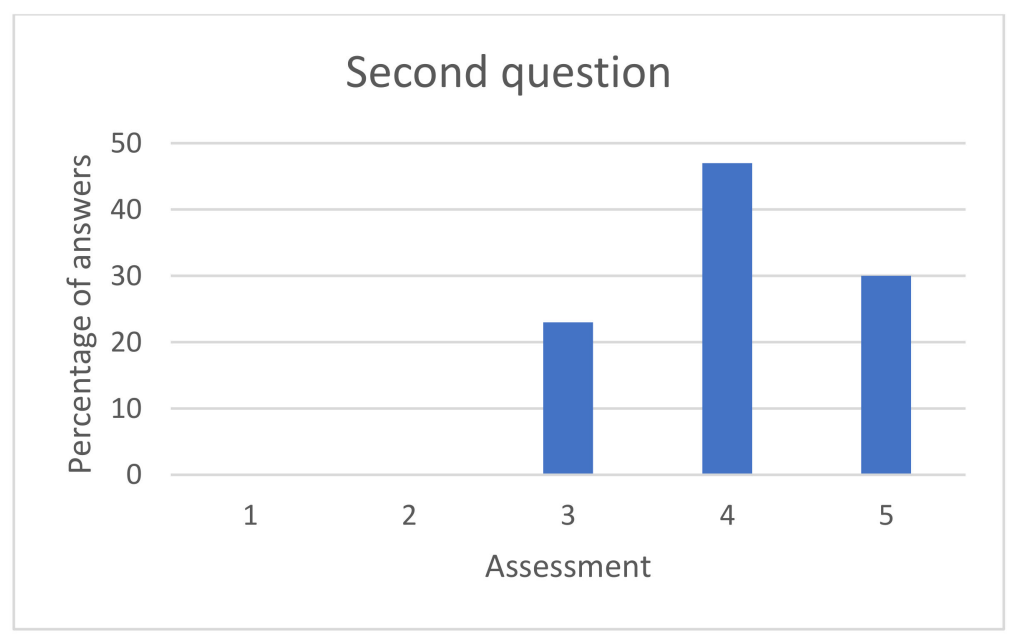

Figure A3. Results of question 2.

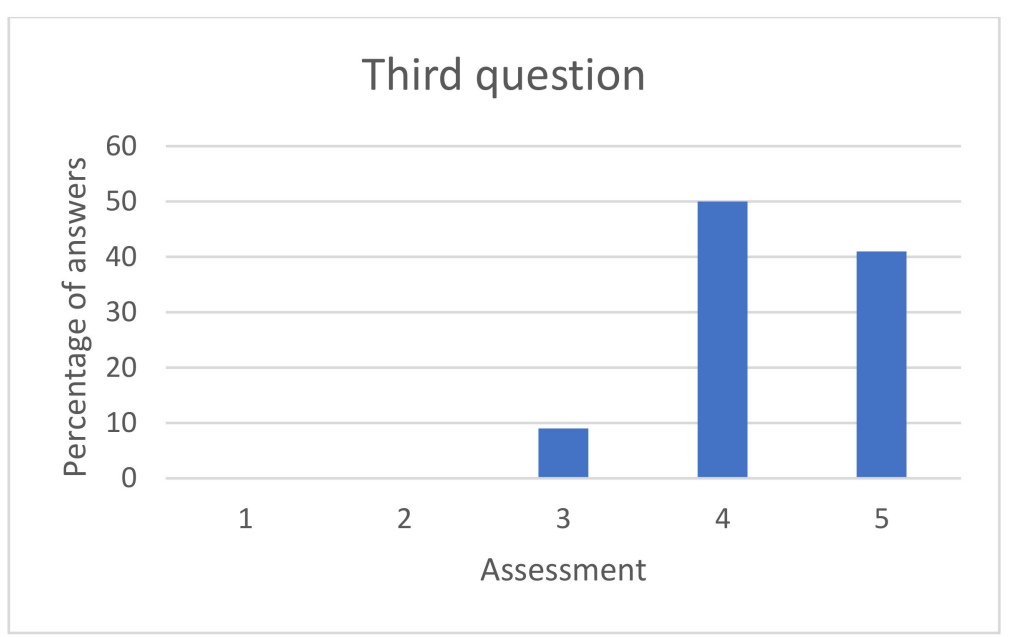

Figure A4. Results of question 3. 


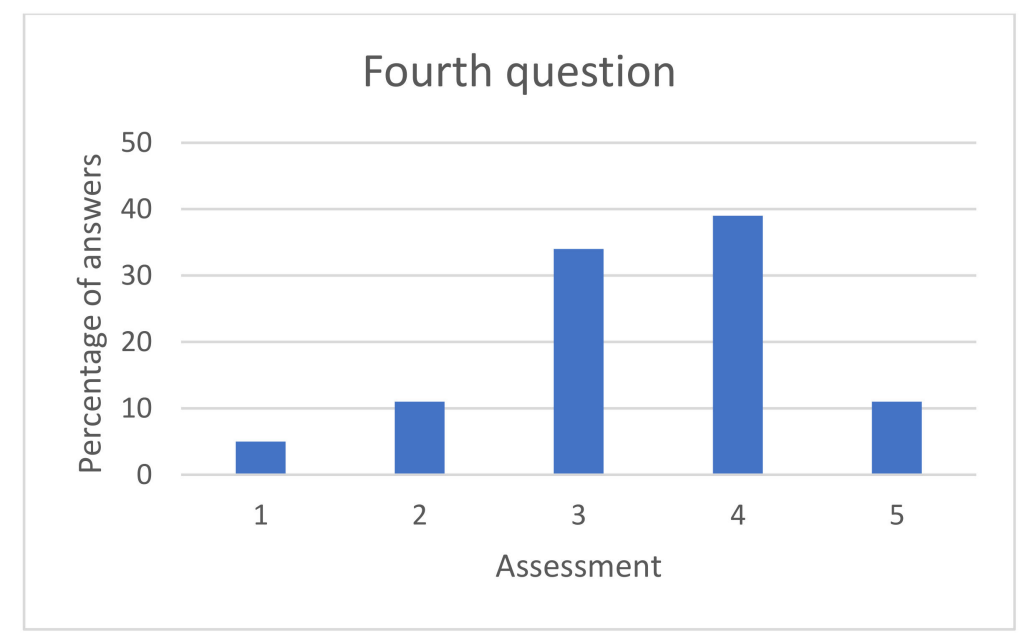

Figure A5. Results of question 4.

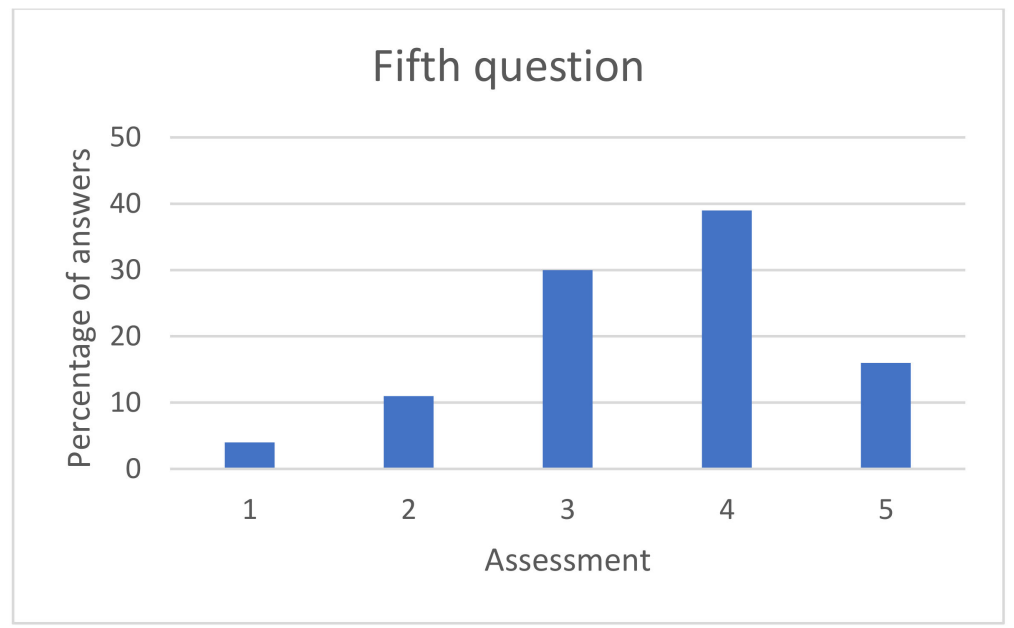

Figure A6. Results of question 5.

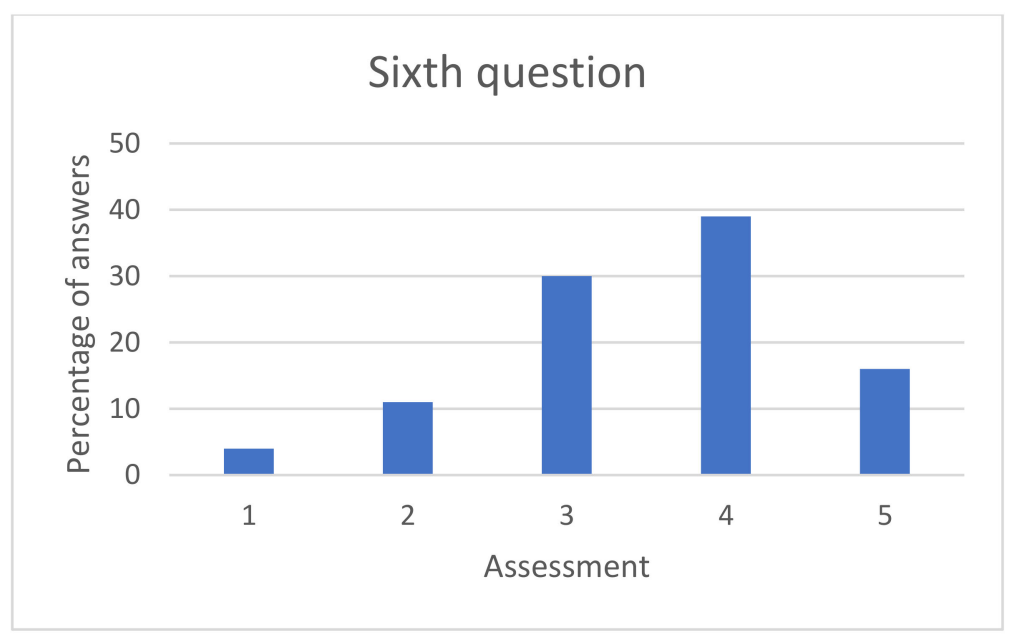

Figure A7. Results of question 6. 


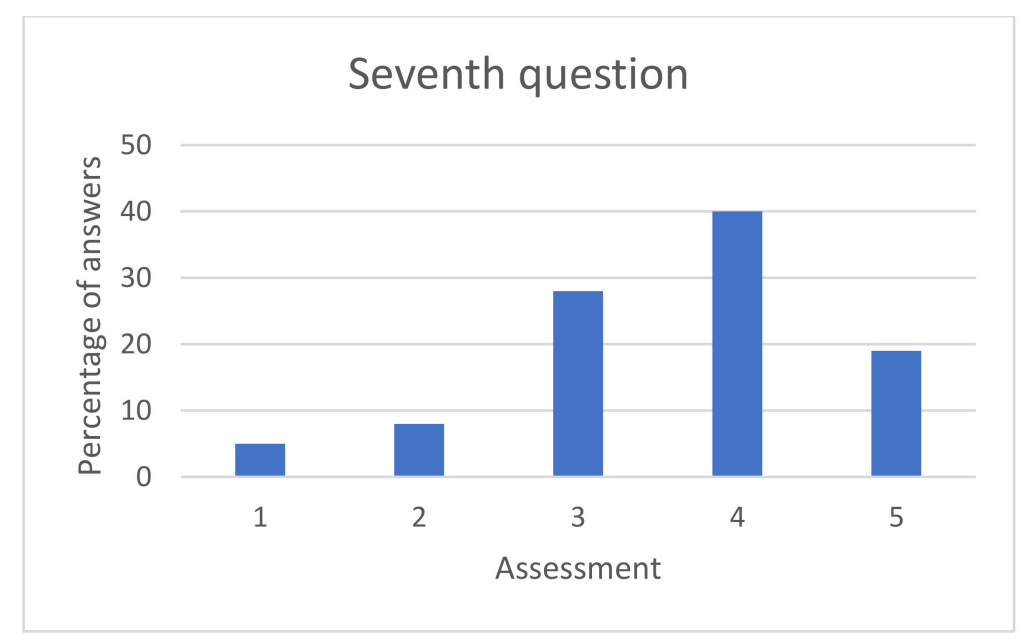

Figure A8. Results of question 7.

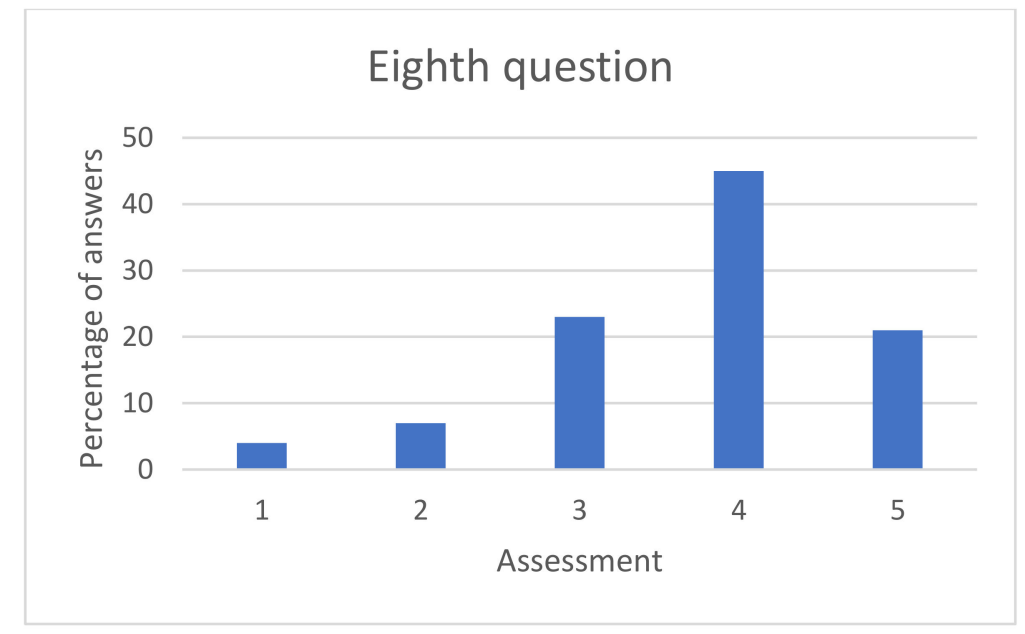

Figure A9. Results of question 8.

\section{References}

1. Huizinga, J. Homo Ludens; Rowohlt Taschenbuch Verlag GmbH: Hamburg, Germany, 1987.

2. Sánchez, D.R.; Langer, M.; Kaur, R. Gamification in the classroom: Examining the impact of gamified quizzes on student learning. Comput. Educ. 2020, 144, 103666. [CrossRef]

3. Kapp, K.M. The Gamification of Learning and Instruction: Game-Based Methods and Strategies for Training and Education; Pfeiffer: San Francisco, CA, USA, 2012.

4. Ouariachi, T.; Olvera-Lobo, M.D.; Gutiérrez-Pérez, J. Evaluación de juegos online para la enseñanza y aprendizaje del cambio climático. Enseñanza Cienc. 2017, 35, 193-214.

5. Martí-Parreño, J.; Méndez-Ibáñez, E.; Giménez-Fita, E.; Queiro-Ameijeiras, C. El uso de la gamificación en la educación superior: Propuesta de una ficha de análisis ludológico-narratológico. In Actas de las XII Jornadas Internacionales de Innovación Universitaria Educar para Transformar: Aprendizaje Experiencial; Rosillo, M., Ed.; Universidad Europea de Madrid: Madrid, Spain, 2015; pp. 103-111.

6. Michael, D.; Chen, S. Serious Games: Games that Educate, Train and Inform; Thomson: Boston, MA, USA, 2005.

7. Gee, J.P. Being a lion and being a soldier: Learning and games. In Handbook of Research on New Literacies; Coiro, J., Knobel, M., Lankshear, C., Leu, D.J., Eds.; Routledge: New York, NY, USA, 2008; pp. 1023-1036.

8. Katsaliaki, K.; Mustafee, N. Edutainment for Sustainable Development: A survey of Games in the Field. Simul. Gaming 2014, 46, 647-672. [CrossRef]

9. Suh, A.; Wagner, C.; Liu, L. Enhancing User Engagement through Gamification. J. Comput. Inf. Syst. 2018, 58, 204-213. [CrossRef]

10. Kalogiannakis, M.; Papadakis, S.; Zourmpakis, A.-I. Gamification in Science Education. A Systematic Review of the Literature. Educ. Sci. 2021, 11, 22. [CrossRef] 
11. Gallagher, K. Problem solving through recreational mathematics. In Problem Solving in School Mathematics; Yearbook; Krulik, S., Reys, R.E., Eds.; NCTM: Reston, VA, USA, 1980; pp. 169-177.

12. Sailer, M.; Hense, J.U.; Mayr, S.K.; Mandl, H. How gamification motivates: An experimental study of the effects of specific game design elements on psychological need satisfaction. Comput. Hum. Behav. 2017, 69, 371-380. [CrossRef]

13. Marín, V. La Gamificación educativa. Una alternativa para la enseñanza creativa. Digit. Educ. Rev. 2015, 27, 1-4.

14. Liarakou, G.; Sakka, E.; Gavrilakis, C.; Tsolakidis, C. Evaluation of serious games, as a tool for education for sustainable development. EURODL 2012, 15, 96-110.

15. Chamoso, J.M.; Durán, J.; García, F.; Martín, J.; Rodríguez, M. Análisis y experimentación de juegos como instrumento para enseñar matemáticas. Suma 2004, 47, 47-58.

16. Dele-Ajayi, O.; Sanderson, J.; Strachan, R.; Pickard, A. Learning Mathematics through Serious Games: An Engagement Framework. In Proceedings of the 2016 IEEE Frontiers in Education Conference (FIE), Erie, PA, USA, 12-15 October 2016; pp. 1-5.

17. Moreno-Guerrero, A.J.; Rondón García, M.; Martínez Heredia, N.; Rodríguez-García, A.M. Collaborative Learning Based on Harry Potter for Learning Geometric Figures in the Subject of Mathematics. Mathematics 2020, 8, 369. [CrossRef]

18. Lantarón, S.; López, M.; Merchán, S.; Rodrigo, J. Gamification actions in the teaching of mathematics at every educational level. In EDULEARN18 Proceedings; IATED: Palma, Spain, 2018; pp. 304-312.

19. Lantarón, S.; López, M.; Merchán, S.; Rodrigo, J. Cajas Lógicas. In Proceedings of the Jornadas: Tendencias en Innovación Educativa y su Implantación en la UPM, Madrid, Spain, 20 November 2018.

20. Lantarón, S.; López, M.; Merchán, S.; Rodrigo, J. Analysis of logical and strategical games as a tool for the teaching and approach to mathematical concepts. In INTED2019 Proceedings; IATED: Valencia, Spain, 2019; pp. 7963-7969.

21. Edo, M.; Deulofeu, J. Investigación sobre juegos, interacción y construcción de conocimientos matemáticos. Enseñanza Cienc. 2006, $24,257-268$.

22. González, A.G.; Molina, J.G.; Sánchez, M. La matemática nunca deja de ser un juego: Investigaciones sobre los efectos del uso de juegos en la enseñanza de las matemáticas. Educ. Matemática 2014, 26, 109-133.

23. Queiruga-Dios, A.; Santos Sánchez, M.J.; Queiruga Dios, M.; Gayoso Martínez, V.; Hernández Encinas, A. A Virus Infected Your Laptop. Let's Play an Escape Game. Mathematics 2020, 8, 166. [CrossRef]

24. Iriondo-Otxotorena, J. Mejora Didáctica en la Transición de la Aritmética al Álgebra en el Primer Ciclo de la ESO Basada en la Ludificación. 2016. Available online: https:/ / reunir.unir.net/handle/123456789/3538?show=full (accessed on 11 March 2021).

25. Yung, O.C.; Junaini, S.N.; Kamal, A.; Ibharim, L.F. Slash 100\%: Gamification of mathematics with hybrid QR-based card game. Indones. J. Electr. Eng. Comput. Sci. 2020, 20, 1453-1459. [CrossRef]

26. Novak, N.; Tassell, J. Using video game play to improve education majors' mathematical performance: An experimental study. Comput. Hum. Behav. 2015, 53, 124-130. [CrossRef]

27. Contreras-Espinosa, R.S. Juegos digitales y gamificación aplicados en el ámbito de la educación. RIED 2016, 19, 27-33. [CrossRef]

28. Guzmán, M. Tendencias Innovadoras en Educación Matemática; Editorial Popular: Madrid, España, 1993.

29. Brull, S.; Finlayson, S. Importance of Gamification in Increasing Learning. J. Contin. Educ. Nurs. 2016, 47, 372-375. [CrossRef]

30. Chu, C.; Hung, C.H. Effects of the Digital Game-Development Approach on Elementary School Students' Learning Motivation, Problem Solving, and Learning Achievement. Int. J. Distance Educ. Technol. 2015, 13, 87-102. [CrossRef]

31. Werbach, K.; Hunter, D. For the Win: How Game Thinking Can Revolutionize Your Business; Wharton Digital Press: Philadelphia, PA, USA, 2012.

32. Oliva, H.A. La gamificación como estrategia metodológica en el contexto educativo universitario. Real. Reflexión 2017, 44, 29. [CrossRef]

33. López, D.; Calonge, A.; Rodríguez, T.; Ros, G.; Lebron, J.A. Using gamification in a teaching innovation project at the University of Alcala: A new approach to experimental science practices. Electron. J. Learn 2019, 17, 93-106.

34. Mansureh, K.; Atsusi, H.; Haiyan, B. The effects of modern mathematics computer games on mathematics achievement and class motivation. Comput. Educ. 2010, 55, 427-443.

35. Ke, F. An implementation of design-based learning through creating educational computer games: A case study on mathematics learning during design and computing. Comput. Educ. 2014, 73, 26-39. [CrossRef] 